\title{
Seventy Years of the Institute of Control Sciences- Seventy Years of Formation and Development of the National Science of Control
}

DOI: $10.1134 /$ S0005117909060010

In 1939 the Council of People's Commissars decides to organize the Institute of Automation and Remote Control on the basis of the Commission for Automation and Remote Control that existed since 1934 within the Department of Technical Sciences of the USSR Academy of Sciences. A former military flyer and by then an outstanding researcher in the field of aviation energetics, Academician Viktor Sergeevich Kulebakin was nominated its first director. The Institute was entrusted with a task to develop the fundamental research in the area of automation and control and relate it with applied problems. From its very beginning, the institute's activity was associated with the internationally renowned researchers such as V.S. Kulebakin, N.N. Luzin, A.A. Andronov, B.N. Petrov, M.A. Aizerman, Ya.Z. Tsypkin, B.S. Sotskov, M.A. Gavrilov, A.A. Fel'dbaum, and many others.

A number of outstanding scientists, both theorists and practitioners of the science of control, grew up or won international recognition at the Institute. Alongside with that, the Institute always invited eminent scientists who were interested in the new area of knowledge and relied on their experience in formulating scientific problems and seeking the paths to resolve them. They contributed to setting up a special creative atmosphere at the Institute and exercised a great influence on formation of the ethical principles of communication in the scientific community. It is namely these outstanding, internationally renowned scientists that assisted in establishing the Institute's professional contacts with the international scientific community. As the result, this country was one of the initiators of creating the International Federation of Automatic Control (IFAC) and organizer of the First International IFAC Congress held in Moscow in 1960.

At the time of organization of the Institute, its personnel included twenty-two employees, including B.N. Petrov (future academician and Vice-President of the USSR Academy of Sciences, and Institute's director in 1947-1951), M.A. Gavrilov (future Corresponding Member of the USSR Academy of Sciences), N.N. Shumilovskii (future member of the Kirghiz Academy of Sciences), professors V.A. Lossievskii, G.V. Shchipanov, and others. Soon the outstanding mathematician, Academician N.N. Luzin joined the Institute. He and later Academician A.A. Andronov brought up a host of brilliant theorists in the field of control.

In the life of the Institute the prewar years were marked by a substantial progress in the description of the control systems in terms of the differential equations and the discussion on G.V. Shchipanov's "compensation conditions" whose satisfaction, as he asserted, would make the automatic control system insensitive to the external disturbances. This discussion was led not only in the scientific publications, but also on the pages of the central communist press. In fact, the Shchipanov conditions were the precursors of what later formed into the invariance theory developed by V.S. Kulebakin, N.N. Luzin, and B.N. Petrov. G.V. Shchipanov died in 1953, and his scientific "rehabilitation" took place in 1960 when a commission of Academicians A.A. Dorodnitsyn, A.Yu. Ishlinskii, and B.N. Petrov corroborated the scientific significance of his discovery. In 
formal terms, the "G.V. Shchipanov compensation conditions" were recognized as discovery in 1966 with priority as of April 1939.

At the war years, the Institute works for front, and some of its future scientific leaders such as M.A. Aizerman, P.P. Parkhomenko, Ya.Z. Tsypkin, and others took arms to defend the Motherland. At the Great Patriotic War, among the most remarkable achievements of the Institute's researchers in increasing the fighting capability of the Soviet Army, one cannot but mention the works headed by the future Corresponding Member of the USSR Academy of Sciences B.S. Sotskov on suppressing the influence-controlled mine-and-torpedo weaponry and the works on automation of quality inspection at production of the large-calibre cartridge cases headed by then-young engineer B.N. Petrov under the leadership of the future Academician V.A. Trapeznikov who headed the Institute from 1951 to 1987 . The group headed by M.A. Gavrilov was responsible for debugging at a military factory the relay hardware and developed methods to suppress noise in the control system of moving objects.

Academician A.A. Andronov joined the Institute after the war. He organized the famous Andronov's seminar through which passed the entire postwar generation of scientific leaders of the Institute of Automation and Remote Control including M.A. Aizerman, A.Ya. Lerner, M.V. Meerov, V.V. Petrov, V.V. Solodovnikov, Ya.Z. Tsypkin, A.A. Fel'dbaum, and may others. In 1969 the Presidium of the USSR Academy of Sciences instituted the A.A. Andronov Prize. A.G. Butkovskii and Andronov's follower M.V. Meerov were among the first its winners.

The most outstanding achievements of the Institute in the 1940-1950s are as follows:

- development of the mathematical apparatus of the algebra of logic for description, analysis, and design of the relay-contact circuits (M.A. Gavrilov);

- development of the general theory of the linear control systems (V.S. Kulebakin, B.N. Petrov, V.V. Solodovnikov, Ya.Z. Tsypkin, M.A. Aizerman, M.V. Meerov, and others);

- development of the theory of nonlinear control systems, including the method of point transformations, theory of absolute stability, and theory of the relay circuits (V.V. Petrov, G.M. Ulanov, A.A. Fel'dbaum, M.A. Aizerman, Ya.Z. Tsypkin);

- theory of analytical design of controllers (A.M. Letov);

- development of the general methods to study the discrete automatic control systems (Ya.Z. Tsypkin);

- development of the fundamentals of the optimal control theory (A.A. Fel'dbaum and A.Ya. Lerner, and later A.G. Butkovskii and V.F. Krotov);

- development of the theory of dual control (A.A. Fel'dbaum);

- design of the first national family of analog computers (B.Ya. Kogan, V.A. Trapeznikov, and others);

- design of basically new sensors, transducers, and instruments (B.S. Sotskov, D.I. Ageikin, M.A. Rozenblat, E.K. Krug, and others).

At the early 1950s, on request of S.P. Korolev and V.P. Glushko the Institute started under the guidance of B.N. Petrov the works on control of the liquid-propellant rocket engines for the first in the world intercontinental rocket R-7. The first results on the problems of propellant consumption, design of the tank draining system, phantom velocity control system were obtained and feasible control system actuators were considered by B.N. Petrov, Yu.P. Portnov-Sokolov, V.V. Petrov, G.M. Ulanov, S.V. Emel'yanov, V.Yu. Rutkovskii, I.N. Krutova, and others as early as in 1953. Later on B.N. Petrov, Yu.P. Portnov-Sokolov, A.N. Chatskin, V.N. Markov, and others developed these results into the principles of design and the theory of the control systems for the liquidpropellant rocket engines. 
The development of the control systems of tank draining and propellant consumption synchronization gave rise to the theory of on-board terminal control systems created by B.N. Petrov, Yu.P. Portnov-Sokolov, A.Ya. Andrienko, V.P. Ivanov, and others.

Development of the general concept of using the control systems to improve the launcher power characteristics was completed by Yu.P. Portnov-Sokolov, A.Ya. Andrienko, V.P. Ivanov, and others in the 1980s.

For the time being, the control systems based on the Institute's studies are the constituents of the larger liquid-propellant rockets developed by the Chief Designers S.P. Korolev, M.K. Yangel', V.N. Chelomei, and V.F. Utkin.

Development of the theory of control of large flexible spacecraft-satellites with large solar panels, extendable radio antennas, and others - was started at the Institute at the mid-1950s. The modal-physical, amplitude, and phase principles of damping the elastic oscillations of the object structure and the method of phase biplane for design of the control algorithms were proposed by V.Yu. Rutkovskii and V.M. Sukhanov.

The problem of joint evaluation of the coordinates of "rigid" and elastic motions of the flexible spacecraft was recently solved by V.A. Sukhanov, T.V. Ermilova, A.S. Ermilov, and others. Control algorithms using elements of the intelligent diagnosis and fuzzy logic-based adaptation algorithms were proposed by V.Yu. Rutkovskii, V.M. Sukhanov, I.N. Krutova, V.M. Glumov, and others.

At the late 1950s, B.N. Petrov, V.Yu. Rutkovskii, I.N. Krutova, S.D. Zemlyakov, B.V. Pavlov, I.B. Yadykin, and others undertook studies of the theory of adaptive control with model. The principles of constructing such systems and linearized system models, "Lyapunov" adaptation algorithms were proposed, and the notion of "generalized" object was introduced together with its structural design on the basis of the invariance theory.

The results obtained were later generalized into the theory of adaptive coordinate-parametric control, theory of adjustable functionality, concept of restorable functionality and adjustable strategy of control; the theory of optimal adaptive controllers was developed. The first Soviet adaptive control systems for a number of major types of flight vehicles were designed on the basis of the theory of adaptive coordinate-parametric control.

In 1980, the USSR Academy of Sciences instituted the B.N. Petrov Gold Medal; since 1993 the B.N. Petrov Prize. The first B.N. Petrov Gold Medal was awarded in 1983 to V.Yu. Rutkovskii. In 2004 the B.N. Petrov Prize was awarded to Yu.P. Portnov-Sokolov, A.Ya. Andrienko, and V.P. Ivanov, in 2007, to V.V. Kul'ba, B.V. Pavlov, and Corresponding Member of the Russian Academy of Sciences, E.A. Mikrin ("Energiya").

Future Academician Ya.Z. Tsypkin developed the general theory of adaptive systems which was a natural continuation of A.A. Fel'dbaum's theory of dual control and later gave rise to the theory of robust systems laid by Ya.Z. Tsypkin and today developed by the Ya.Z. Tsypkin laboratory under the leadership of B.T. Polyak. The point is that the classical theory usually assumes that the system model is known or estimated in the course of identification, whereas in real fact all object characteristics have unavoidable imprecisions. The robust theory which attracts great interest of the researchers proposes methods to allow for such uncertainties. If at the first years of studies attention was focused on analysis (robust stability), now consideration is given to the important problem of design (robust control). The notion of super-stability (sufficient stability condition formulated in terms of the linear conditions for the elements of the system matrix), probabilistic approach, and numerical methods proved to be useful for solving the trying problems of robust control. The classical theory of $D$-decomposition developed at a new level in the works of the laboratory researchers proved to be a handy tool suited to solving the modern problems of analysis and design of the robust systems. 
Since in the course of development of the theory of automatic control it became clear that its classical methods are insufficient for calculation of complicated automatic systems operating under random actions, Academician V.S. Pugachev and his colleagues created the general theory of stochastic system control. Use of the probabilistic methods enabling one to allow for the effect of diverse random perturbations and noise on the automatic systems and their components was a natural step in the development of the control systems and processes. As the result, an important path of research, the theory of stochastic control processes which leans heavily on the methods of the probability theory and mathematical statistics, appeared within the framework of the general theory of processes. The Institute's works in the field of stochastic problems of control gave a powerful impetus to its development, substantially enriched it, and lead to appearance and development of new divisions.

The theory of statistically optimal systems was an important field of the Institute's research. Within the framework of this theory, the methods for design of optimal nonstationary and nonlinear systems (V.S. Pugachev, L.P. Sysoev), new efficient methods of nonlinear filtering and extrapolation of random processes (R.Sh. Liptser, A.N. Shiryaev, V.S. Pugachev), and methods of statistical optimization by various performance criteria (N.I. Andreev) were developed. Efficient approximate methods of calculation and analysis of multivariable nonlinear systems subjected to random actions (M.L. Dashevskii, R.Sh. Liptser) were developed at the Institute. V.S. Pugachev developed the statistical theory of learning and self-learning of the automatic systems operating in the conditions of incomplete information and, together with I.N. Sinitsyn, laid the groundwork of the general theory of stochastic systems. The last period in the development of the stochastic control theory is characterized by great interest to the design of automatic systems under parametric and nonparametric uncertainty. Developed were the fundamentals of the theory of stable nonparametric estimation of the functional of unknown distributions which underlies the theory of nonparametric estimation of the random processes with unknown probabilistic characteristics (A.V. Dobrovidov, G.M. Koshkin, V.A. Vasil'ev).

N.S. Raibman, one of V.S. Pugachev's followers, applied much effort to provide the designers of the control systems of various physical objects with effective tools such as the methods to construct the mathematical models of the control plants from experimental statistical data and the identification theory (S.A. Vlasov, V.A. Lototskii, A.S. Mandel', V.M. Chadeev).

The studies on the stochastic robust control for the discrete stationary linear systems were started at the Institute in 1992 in continuation of the ideas of the $H_{\infty}$-control theory that were heatedly discussed during 1991-1992 at A.S. Poznyak's seminar. In collaboration with I.G. Vladimirov (Institute for Information Transmission Problems of the Russian Academy of Sciences) and A.V. Semenov (State Research Institute of Automatic Systems), A.P. Kurdyukov developed the theory of constructing the stochastic control systems that are robust to the characteristics of the random input disturbance.

The above theory was christened by its authors the anisotropic control theory ${ }^{1}$ because it relies on the notion of signal anisotropy characterizing the deviation of the probability distribution of the multivariable input signal from the multivariable signal which is distributed by the normal law with zero mean and scalar covariance matrix and is isotropic in a sense. The anisotropy control theory lies in between the theory of design of the Gaussian linear-quadratic controllers and the $H_{\infty}$-control theory. Additionally, both theories are special cases of the anisotropy theory for anisotropy tending, respectively, to zero or infinity.

The anisotropy theory combines the advantages of both theories and enables one to design controllers that are less conservative than the $H_{\infty}$-controllers and more robust than the linear-

\footnotetext{
${ }^{1}$ Anisotropy is the characteristic of a substance for which a physical property varies in value with the direction in or along which the measurement is made.
} 
quadratic Gaussian controllers. The constructed theory demonstrated its validity in the designs of controllers for aircraft landing in the environment of uncontrollable disturbances.

In 1957 the future Academician S.V. Emel'yanov was the first in the world to propose the unstable motions and structures to improve performance of the transient processes in the automatic control systems. In the 1960s S.V. Emel'yanov and his school developed this idea up to the theory of variable-structure systems. The topical problems of the control theory such as stabilization of essentially uncertain systems, design of the tracking system featuring high astaticism, filtering and differentiation in uncertain noise, and others were effectively solved in the class of variable-structure systems.

Since the early 1960s, on the initiative of A.A. Fel'dbaum and M.A. Aizerman the Institute undertook intensive studies on the pattern recognition theory, automatic classification, self-learning systems, and methods for complex data processing. The fundamental works carried out in some laboratories by Ya.Z. Tsypkin and G.K. Kel'mans, M.A. Aizerman, E.M. Braverman, L.I. Rozonoer, and B.M. Litvakov, V.N. Vapnik and A.Ya. Chervonenkis, A.A. Dorofeyuk, I.B. Muchnik, and E.V. Bauman deserve mentioning.

The Institute pioneered in the internationally recognized wide area of scientific research on "Optimal control of the distributed-parameter systems" (A.G. Butkovskii). Simple listing of the important scientific, engineering, and technological applications of this discipline where the Institute took part would be too long: metallurgy, chemistry, machine building, space engineering, economics, and others.

In what concerns the theory, the problems of optimal control of the distributed-parameter systems are related with the delay partial differential equations, integral and integro-differential equations, functional equations, and some other mathematical disciplines such as the number theory, fractals, and others. In what concerns physics, these problems are related with the control of fields and continuous media of various, including nonclassical, nature.

For the time being, there are thousands of publications in the world that are devoted to this scientific and applied field. More than ten monographs on this subject was written at the Institute. Eight of them were translated in the USA, Great Britain, Holland, and Finland. Special mentioning is deserved by the monograph Control of Quantum-mechanical Systems written at the Institute in 1984 on the basis of the papers of 1979 which was translated in the West and recognized internationally as pioneering in this field. This problem seems now to be the key one in the field of the modern nanotechnology.

The mathematical specificity of the Institute's studies headed by V.F. Krotov comes to formulating the conditions for global optimality of control of the dynamic systems and creating on this basis the apparatus for solution of the corresponding problems. Everything began from the creation and study of this apparatus for the determinate dynamic systems obeying the ordinary differential equations. Then, the first results were generalized, on the one hand, "deep down" in the direction of their association with the necessary conditions for minimum of the functional of variational calculus and the optimal control theory up to getting unique necessary and sufficient conditions, and "in breadth," on the other hand, and extended to new classes of problems with distributed parameters, incomplete information, and so on.

The equations of the optimal control theory are extremely complicated, and their solution gives rise to numerous calculational problems - the calculational methods to design the permissible and optimal controls - which make up the subject matter of the applied part of this theory. New efficient universal methods were developed for successive improvement of control based on these ideas and supported by the experience gained in computations and the corresponding software.

This direction of the mathematical theory of optimal control is developed in collaboration with some scientific teams of the Russian Academy of Sciences and the universities of this country, CIS, 
Germany, USA, Israel, and others. The Institute plays a leading part in the complex of studies in this field which is of international interest. This interest is reflected in numerous monographs, text books, reviews, and papers developing and describing the corresponding results. Detailed analysis of the results of studies in this field and its applications can be found in the V.F. Krotov's monograph Global Methods in Optimal Control Theory, New York: Marcel Dekker, 1996.

The mathematical results obtained were used to investigate the following applied scientific and technical problems:

(1) optimization of the trajectories of moving objects, analysis and design of their control systems;

(2) modeling and analysis of the development of a diversified economy;

(3) design and optimization of the control of substance quantum state.

Among the problems of class (1) we focus on those of the optimal maneuvering control of a flight vehicle in the terrestrial atmosphere by means of programmed changes of the engine thrust and angle of attack. Calculations of such maneuvers are repeatedly carried out in the engineering practice for flight vehicles of various classes ranging from spacecraft to aircraft. Solutions of these problems using the principle of maximum and other methods of local optimization are discussed in numerous publications. The proposed approaches differ from other their counterparts because they consider the problem of seeking the absolute maximum, have advanced analytical part of solution, are simple algorithmically and, in particular, have no boundary-value problems.

The nonlinear optimization models of the development of diversified economy were carried out within the framework of direction (2).

The applied direction (3) is of special interest. A vast domain of new physical technologies based on the control of substance quantum state by subjecting it to electromagnetic field is thriving today. They include synthesis of new materials using physical, rather than chemical, means, separation of isotopes, photochemistry, and others. The mathematical algorithm to design such control is an important component of nanotechnological design.

It is generally agreed by the physicists that the methods of optimal control theory offer an adequate apparatus for such design. The corresponding problems are described by systems of nonlinear differential equations of thousand-fold orders. Solutions of such problems were examined using the successive improvement methods developed under the guidance of V.F. Krotov. Their publication in the 1990s stimulated a wave of physical studies and publications in the leading international physical and physico-chemical journals. All these publications agreed that the methods developed at the Institute open the best way to solving the corresponding problems. The latest of such paper came off the press in 2008 in Physical Review.

At the late 1960s, M.V. Meerov headed the fundamental studies on design of the optimal multivariable control systems (future Academician O.I. Larichev, V.N. Kulibanov, Ya.M. Bershchanskii, and R.T. Yanushevskii) using, in particular, the conditions of A.A. Milyutin and A.Ya. Dubovitskii, the R. Bellman principle of optimality, and the L.S. Pontryagin principle of maximum. The results obtained served as the basis for the development of the methods and algorithms to design the systems of optimal dynamic control of the hydro-dynamic processes of filtration at oil-field development.

The fundamental studies of the problem of modeling and control of the nonlinear dynamic multivariable large-scale systems were started in the 2000s by A.V. Akhmetzyanov and V.N. Kulibanov. The results obtained corroborated the need for developing new principles of modeling and optimal process control with regard for the structural and physical characteristics of the state space, properties of the moving substances, and nature of the permissible control actions. 
The works on the design of the first in the world integrally automated nuclear submarine (Project-705) played a key role in forming in the Institute's collective the taste for tackling complicated problems of control of the most important economic objects. All works on the new submarine were headed by Academician A.P. Aleksandrov, automation was headed by Academician V.A. Trapeznikov. Later these studies found continuation in the designs and perfection of the nuclear ice breakers "Arktika" and "Sibir'," as well as in the new large-capacity tankers and container ships, and changed dramatically the seamen's concepts of the component reliability. In the course of implementing Project-705, it became clear that the human factor is pivotal to increasing effectiveness of the of combat missions, especially in the extremal situations (at that time up to $70 \%$ of the emergency situations were created by human operators). A special team headed by D.I. Ageikin was organized. Its development works such as the scaled-down simulator stands, procedures for professional screening of the operators, selection of the hardware for visualization, and the nature of information display enabled a dramatic improvement in the effectiveness and reliability of the human operator and combat operator teams with simultaneous dramatic (triple) reduction in the number of the nuclear submarine personnel. And many other ideas, programs, and entire lines of research were developed for the first time, and some of them remain still topical and find wide use until now.

Another example of such complex effort is offered by the "Zapchast'" project for the USSR national economy aimed to solve the problem of spare part supply for various machines and equipment including those of twofold purpose. The work was carried out in 1971-1975 by a team of Institute's workers headed by A.A. Dorofeyuk. V.A. Trapeznikov contributed very much to its success. Being then the First Deputy Chairman of the State Committee of the USSR for Science and Technology, he managed to draw attention of A.N. Kosygin and D.S. Polyanskii (then the First Deputy of the USSR Council of Ministers) and some first leaders of several Union Republics and larger regions of Russia to this problem.

Design of the computer-aided information and control systems (A.F. Volkov, A.G. Mamikonov, V.V. Kul'ba, A.D. Tsvirkun, O.I. Aven, V.L. Epshtein, and others) was initiated in the 1960s and goes on until now. The automatic control systems "Metall" for supply of the metal products in this country, "Morflot" (marine), "Obmen" (exchange), and others exemplify the first uses of such systems.

The automatic seat reservation system "Sirena" designed for "Aeroflot" in the late 1960s-early 1970s played an important role in automation of the mass servicing processes. V.A. Zhozhikashvili was appointed the General Designer of "Sirena" by the decision of the USSR Council of Ministers, an important part in introduction of the developed methods of automation was played by V.A. Kucheruk.

Studies on control of safety of the complex systems were initiated in the mid-1980s (V.V. Kul'ba, A.Ya. Andrienko, V.N. Burkov, B.G. Volik, V.G. Lebedev, Yu.S. Legovich, and others). This work goes on until now. The most serious results are those related with the solution of the problem of informational safety and safety control in emergencies.

Well known are also the fundamental achievements of the Institute in the domain of the reliability theory (B.S. Sotskov, B.G. Volik, S.M. Domanitskii, I.E. Dekabrun, B.P. Petrukhin) and technical diagnosis (P.P. Parkhomenko, E.S. Sogomonyan, M.F. Karavai, and others).

The developments of new technical facilities and automation systems were and still are carried out along an extended front. An active part in them was played by Academician of the Georgian Academy of Sciences I.V. Prangishvili who headed the Institute in 1987-2006. The concept of uniform logical and computing microelectronic structures was advanced at the early 1960s under the leadership of I.V. Prangishvili. It underlies the computer systems of the PS family (PS-2000 and 
PS-3000). The PS systems were commensurable in performance with the most powerful domestic computer systems of the corresponding classes and featured the best performance/cost ratios.

B.S. Sotskov's idea of unification of the process automation facilities on the basis of the blockmodular principle that was advanced as early as in the 1950s underlay the unified aggregate instrumentation system. Its development lead to the State Systems of Industrial Instrumentation and Means of Automation GSP-1 (1960-1970s) and GSP-2 (1980-1990s).

Much progress was made in the area of design of sensors and instrumentation (D.I. Ageikin, V.Yu. Kneller, and others ), magnetic and semiconductor elements (M.A. Rozenblat, N.P. Vasil'eva, and others ), means of automatic analysis (BARS system), relay circuits (M.A. Gavrilov, P.P. Parkhomenko, and others), elements of pneumatic automation (M.A. Aizerman, A.A. Tal', A.A. Tagaevskaya, T.K. Berends, and T.K. Efremova). Many of these works today find continuation in the form of nanotechnological magnetic elements (S.I. Kasatkin), fluidic devices (A.M. Kasimov), and radio wave sensors (B.V. Lunkin).

The aggregate-integral fluidic technology (AIST) for control of the parameters of aviation engines using the turbine air at the temperatures up to $500^{\circ} \mathrm{C}$ (sometimes, $950^{\circ} \mathrm{C}$ ) under vibrations and shocks in a wide spectrum of radiation was developed under the leadership of A.M. Kasimov. On the basis of the Institute's developments, the "Omsk MKB" (Omsk) and "EGA" (Moscow) companies manufacture more than twenty fluidic controllers for the guiding device, compressor, and other units that are operated on YAK-42, IL-86, IL-96, "Ruslan," AN-70, Tu-204, and other aircraft. For the last twenty years the fluidic controllers worked without failures for more the 20 millions of hours.

The laboratory of the wave methods and information acquisition means (B.V. Lunkin) develops the theory of design of the radio wave sensors and its applications to the problems of parameter measurement and state recognition of the checked and controlled objects. The sensor includes an electrodynamic system serving as the sensitive element and electronic facilities for formation and transformation of the primary information. The structure of the sensitive element is defined by the checked object, measured value, and environmental conditions. Developed were the principles of designing sensors with different parameters, the fundamentals of the theory of invariant measurements, and the theory of the propellant stock sensors in weightlessness which found use, in particular, in the commercial production of some information-and-measurement systems for rocket space systems where the laboratory took an active part.

New generations of the analog-digital devices, the hybrid computer systems GVS-100 and GVS "Rusalka" (B.Ya. Kogan) were created in the 1970s.

One more achievement of the Institute is represented by the system of parallel-structure programmable automation (SPA-PS) designed because in 1986 the Institute was made the scientific leader of the program for design of the automatic process control systems for the prospective nuclear power plants. The SPA-PS concept was developed by M.A. Gavrilov's followers A.A. Ambartsumyan and others. Another project realized by his followers (O.P. Kuznetsov, A.K. Grigoryan, and others) and based on their concept of the programming languages of the logic devices led to the design of the programming automation system for numerically controlled machines that were in commercial production in the 1980s.

The Institute's studies of the properties of the semiconductor structures with specific currentvoltage characteristics (V.D. Zotov) gave rise to basically new multifunctional semiconductor Z-sensors.

In the 1970s the study of the human role and participation in the control loop and in analysis and perfection of the administrative and socio-economic systems became an important path of research. The pioneering works of D.I. Ageikin and the today works of A.D. Tsvirkun and V.K. Akinfiev, F.F. Pashchenko, V.B. Gusev, V.V. Pavel'ev, A.S. Mandel', E.A. Trakhtengerts and V.G. Lebe- 
deva, A.A. Dorofeyuk and A.L. Chernyavskii, V.N. Burkov, D.A. Novikov and A.G. Chkhartishvili deserve special metioning.

The works on the choice theory (M.A. Aizerman, A.V. Malishevskii, and F.T. Aleskerov) and the methods of decision support (A.S. Mandel', A.A. Dorofeyuk, and A.L. Chernyavskii, V.N. Burkov, A.V. Shchepkin, and A.Yu. Zalozhnev) side with them.

Essential results were obtained in the field of control for the biological, medical, and health-care problems. The laboratories of M.A. Aizerman. N.V. Pozin, A.M. Petrovskii, and A.A. Fel'dbaum commenced studying these problems since the 1960s. Later on the front extended. Today the problems related with various aspects of control in the biomedical systems are actively pursued at several Institute's laboratories. Intersecting results were obtained in various years by A.A. Desova, team of the employees of laboratory 25 headed by E.A. Andreeva and O.E. Khutorskaya, V.N. Novosel'tsev, A.I. Yashin and A.I. Mikhal'skii, A.A. Dorofeyuk, I.B. Muchnik and S.M. Borodkin.

Studies of the decompositional design of the control systems within the framework of the block approach are carried out under the guidance of V.A. Utkin since the mid-1990s. This approach relies on the structural properties of the control plant operator and provides a constructive methodological basis for analysis and design of the control system of linear and nonlinear multidimensional multichannel objects of automatic control operating in the conditions of uncontrollable external disturbances, parametric uncertainty, and incomplete measurements. By the present time, developed were the decomposition algorithms of feedback design for some fundamental problems of the control theory such as stabilization, invariance, observation, real-time identification, tracking, and their combinations which enable one to decompose the large design problems into independent elementary subproblems of smaller dimensions. Additional use of the methods of the theory of discontinuous control systems operating in the sliding mode in the problems of both control and observation enables one to make the closed-loop systems robust and invariant. The proposed algorithms are sufficiently easily realizable and allow one to reduce the volume of the a priori information about the control plant and its operational environment. The developed theoretical methods and general algorithms for the mathematical models of the dynamic systems are used in some applications where controlled are the manipulating robots, internal combustion engines, electric drives of various types, and other technical processes.

After the death of Iveri Varlamovich Prangishvili, at the end of 2006 Academician Stanislav Nikolaevich Vasil'ev was elected the Director of the Institute. The Institute activated the fundamental studies in various fields of the control theory and its applications including the following major paths of its scientific activity approved by the Presidium of the Russian Academy of Sciences on March 18, 2008:

- theory of systems and the general control theory,

- methods of control of complex technical and man-machine systems,

- theory of control in the interdisciplinary models of the organizational, social, economic, medicobiological, and ecological systems,

- scientific fundamentals of the control technologies for moving objects and navigation,

- theory and methods of development of the firmware, technical control facilities, and complex information and control systems,

- scientific fundamentals of the integrated control systems and process control automation.

The theory of linear automatic control systems is now developed under the leadership of B.T. Polyak. Attention of the researchers is focused on the trying topical problems such as design of controllers of a given structure - low-order controllers, in particular, design of outputstatic controllers, simultaneous stabilization, and control under persistent perturbations. They succeeded in developing several effective approaches to them. First, these trying problems may be solved in terms of superstability using the linear programming. Second, a probabilistic approach to 
these deterministic problems was proposed. The randomized algorithms proved to be very efficient for many problems of control and optimization.

Studies on the theory of optimal control systems are carried out under the guidance of V.F. Krotov. In particular, developed are the methods of variational calculus and the optimal control theory, as well as algorithms to design and optimize control of diverse - technical, physical, or economicobjects.

Among the burning theoretical and applied areas of research, the unique geometric control theory, theory of nonclassical fractal controls that substantially expands the class of particular applications, theory of moving control that gave rise both to a wide class of applications and an entire class hard mathematical problems such as A.G. Butkovskii's nonlinear problem of moments are intensively explored at the Institute.

Fundamental studies related with the development of the principles of multilevel hierarchical decomposition and splitting of the nonlinear operators in the functional spaces with parallelized computations on the multiprocessor computing systems in different program environments (A.V. Akhmetzyanov) are carried out at the Institute. They are oriented to developing universal principles of modeling and optimal control of the nonlinear multivariable large-scale systems such as the processes of fluid (liquids and gaseous hydrocarbons) filtration in the porous media of the reservoirs of hydrocarbon fields with the geological and geometric conditions of occurrence of any complexity. At that, the role of control actions is played by the displacement agent.

The anisotropic theory was extended to the systems with parametric disturbances (A.P. Kurdyukov). Design of anisotropic controllers requires solution of a system of the Riccati equations, Lyapunov equations, and a special algebraic equation, for which purpose a procedure to solve such equations by the homotopy method was developed and the applied software was created. Studies are carried out on the theory of suboptimal anisotropic control theory, anisotropic control theory for the algebro-difference systems, and reduced-order anisotropic controllers.

Fundamental research of solutions of the $N P$-trying problems of the discrete and combinatorial optimization (A.A. Lazarev) is going on. The results obtained are used to solve the practical problems of the scheduling theory and schedule construction. For the minimax problems of the scheduling theory, a metric was introduced for the first time. The methods of parameter variation and dynamic programming, as well as other modern methods of investigation are used to solve them. For the time being, the nature of complexity of the classical combinatorial problems is studied, and algorithms to solve large-dimensionality applied problems in an acceptable time with guaranteed error of the objective function are developed. Close relations have been established with the leading scientific schools of Germany, France and Great Britain.

Studies of the mathematical models of the infrastructural control systems are carried out. New principles of constructing systems of automatic control of frequency and power of large power unions on the basis of new highly precise measurers coordinated with the astronomic time and new methods of controller design using solutions of the optimization problems with constraints were proposed (I.B. Yadykin).

Theoretical fundamentals of development and study of the game-theoretic and optimization models of control of interdisciplinary (organization technical, socio-economic, ecologo-economic) systems are actively elaborated under the guidance of Corresponding Member of the Russian Academy of Sciences D.A. Novikov. Proposed were original methods of analysis, design, and optimization of the hierarchical, multicomponent, dynamic, and distributed organization systems, including those operating under uncertainty, cooperative or competitive interaction of their elements with allowance for communicative support and informational counteraction (D.A. Novikov, V.N. Burkov, M.V. Gubko, N.A. Korgin, S.P. Mishin, and A.G. Chkhartishvili). They underlie complexes of applied control mechanisms whose effectiveness was corroborated by the development and intro- 
duction of the management mechanisms at the federal, regional, and corporate levels (V.A. Irikov and A.V. Shchepkin).

Nonholonomic and other mechanical systems are studied under the leadership of L.B. Rapoport. The well-known problem of control of the nonholonomic system with rolling - stabilization of motion of the wheel system along the given trajectory - was solved. The law of control stabilizing motion of the wheel system along a planar smooth curve was constructed. Stability in the large is provided for the main variables. Stability of the wheel system with allowance for the errors of measurement of the state variables was substantiated. Methods to estimate the stability domain of the wheel system under constrained control were developed, as well as numerical methods to estimate the domains of stability and reachability. The laws of control with regard for the phase constraints on the wheel system states were constructed. For example, controls in the class of piecewise-linear functions with saturation were designed with the aim of allowing for the limitedness of the angle of rotation of the leading wheels. Applied robust control laws are developed for the wheel systems such as the mobile autonomous robots.

In the area of stability, resonances, and control of the mechanical systems, in particular, consideration is given to the sufficient conditions for origination of isolated oscillations and their stability at an ordinary family point in the general system, scenarios of oscillation origination for the critical family point, constructive conditions for origination and stability of oscillations both in the nonresonance and resonance cases in the general system, conditions for stabilization of oscillations of a system consisting of weakly connected subsystems (V.N. Tkhai).

Under the guidance of S.K. Danilova, methods to determine the extremal characteristics of the optimal control of moving marine objects are developed with the aim of constructing effective algorithms to realize the principle of maximum. Developed is a procedure to design suboptimal control of moving marine objects with the use of the estimated extremal properties of the optimal control and the given estimates of the current and forecasted situations in terms of the hardware and object control systems, environmental actions, and hypothesized variants of situation development in the off-design and emergency modes. Algorithms to design alternative safe motion trajectories are developed with the use of the suboptimal control methods and dynamic estimates of the current and forecasted situations constructed using the dynamic production-type experts systems.

Methods to construct sophisticated firmware complexes for the process control systems are developed and studied along with their characteristics. For the new generation of the control systems, theoretical studies of the methods of construction of the knowledge bases with the use of the fuzzy logic, modeling of the control objects on qualitative scales, automatic generation of the knowledge bases relying on the accumulated experimental data are carried out. Software systems enable one to design the turnkey automatic control systems with built-in knowledge bases for the early diagnosis and other problems. Practical importance of the results obtained lies in the possibility of using this methodology to design a breadboard of a complicated firmware system of control dangerous objects which meets the modern requirements on the open systems (process control systems of the nuclear power stations in the Russian Federation, Iran, and India-N.E. Mengazetdinov and A.G. Poletykin).

M.Kh. Dorri heads the development of the theoretical fundamentals of research complexes and stands for analysis, design, and debugging of the algorithmic support and the software of the intelligent control systems of the sophisticated technical complexes using the integrated data processing systems based on the following:

- block-hierarchical structuring of the problem,

- combined calculation of continuous and logic processes,

- object visualization,

- organization of multilevel interaction of blocks between themselves and the system, 
- interaction of the instrumental system with the databases and modules simulating the objects under consideration and enabling easy reconstruction of the problems at hand.

For a new kind of devices, the tunnel sensors based on the magnetic quantum points whose magnetoresistive properties were detected by the researchers of the Lebedev Physical Institute of the Russian Academy of Sciences, guerrilla work that has no counterparts in the world is carried out together with the Lebedev Physical Institute and the MIET Technological Center. This work is carried out with the aim of obtaining and studying the nanoelements based on the magnetosemiconductor magnetoresistive nanostructures. The nanosensors under design would compete the anisotropic and spin-valve magnetoresistive sensors of magnetic fields and currents (S.I. Kasatkin).

A concept of the new Internet service and principles of construction of the special-purpose facilities and technologies to support the remote interactions in the heterogeneous information and network environment have been developed for solution of the following system problems (V.N. Lebedev):

- design of a simple and intuitively understandable facility for network support of the distributed applications and multiagent systems,

- protection against loss of data in sub-quality communication channels (reliability and network failure tolerance),

- design of interserver data routing applicable both to on-line and off-line interactions.

Multichannel radio-wave sensors of fuel stock in variable-configuration tanks, position of the interfaces and invariant level measurements, thickness of coverings and loose materials, and volume content in the multicomponent emulsion and laminated flows (B.V. Lunkin) have been developed recently. Algorithms ranging from simple (linear combination of two frequencies) for temperature compensation to complex (equation systems) for determination of the fuzzy interfaces of layered media are important elements of these sensors. New work is carried out to design combined sensors based on excitation of electromagnetic and acoustic oscillations in the resonance mode. They are especially important for parameter measurement in multicomponent nonstationary flows.

For the subsystems of the control system of the dispatcher service of the Moscow Department of the Housing-and-Communal Services and Beautification, software and algorithmic support was developed with formalization of the technological processes of snow removal in larger cities beginning from the problems of planning the amount of work to the problems of expeditious control of snow removal (G.G. Grebenyuk). The first stage of the information system for town planning of the municipal formations was put in commission. It is intended for the Committee of Architecture and Town Planning of the Surgut region of the Khanty-Mansiisk Autonomous District and is one of the first in the Russian Federation. Proposals were prepared for the complex innovation program of development of the Moscow megalopolis "Complex of Priority Innovation Projects for Higher Efficiency of Megalopolis Control and Life-support." The program is oriented to development of breakthrough innovation projects and, from the system and control standpoints, encompasses the fundamentals of Moscow life activity with regard for the current tendencies to globalization and world development for social protection of the population and provision of higher level of stable municipal development.

Joint scientific projects were formed together with the Ukrainian National Academy of Sciences (co-manager-UNAS Academician V.M. Kuntsevich) and Belarus National Academy of Sciences (co-manager-BNAS Corresponding Member F. M. Kirillova). The leading scientific school of stability and control in the heterogeneous and some other models of the dynamic and intelligent systems is developed in collaboration with the Institute of System Dynamics and Control Theory (Siberian Branch, RAS, Irkutsk, Russia) that previously was headed by S. N. Vasil'ev and now, by the Corresponding Member of RAS I.V. Bychkov. Thirty-five reports of the Institute's workers were on the program of the XVII IFAC Congress held in July 2008 in Seoul, Republic of Korea. The 
compositions of the Scientific RAS Council for Theory of Controlled Processes and Automation and the Editorial Board of "Avtomatika i Telemekhanika," the first in the world journal on automatic control which was founded as early as in 1936, Editor-in-Chief S.N. Vasil'ev, were renewed and extended.

Since 2009 the Institute works on three Programs of the RAS Presidium:

- "Mathematical Theory of Control," coordinated by Academician N.N. Krasovskii;

- "Scientific Fundamentals of Efficient Nature Management and Development of the Mineral Resources, Development of New Sources of Natural and Anthropogenic Raw Materials," coordinated by Academician D.V. Rundkvist;

- "Fundamentals of Basic Research on Nanotechnologoes and Nanomaterials," coordinated by Academician Zh.I. Alferov.

Institute's employees also are engaged in two programmes of the Department of Power Engineering, Machine Building, Mechanics, and Control Processes, RAS:

- "Motion Control, Theory of Complex Information-and-Control Systems," coordinated by Academicians S.N. Vasil'ev and A.B. Kurzhanskii;

- "Problems of Control and Safety in Power Engineering and Technical Systems," coordinated by Academician F.L. Chernous'ko and Corresponding Member N.A. Makhutov.

Fundamental and applied studies are carried out by the Institute within the bounds of three regional programmes, the Seventh Framework Program of EU and Russia, on orders of the Defense Ministry, Internal Affairs Ministry, Federal Nuclear Power Agency, Federal Space Agency, National Interpol Bureau, and many other organizations and agencies. The Institute's workers participate in the works funded by thirty five projects of the Russian Foundation for Fundamental Research and five international agreements.

The system of propellant consumption control and basically new pneumo-hydraulic propellant supply system using new continuous pressure sensors and algorithmic means for diagnosis and parrying of the failures in the measurement channels and actuators were developed within the bounds of the Russian Federal Space Program for 2006-2015 for the advanced three-stage "Angara" launcher (as applied to the "Angara-A5" version) designed at the M.V. Khrunichev State R\&D Space Center. These systems are intended for a substantial improvement of the rocket power characteristics, maintenance of anticavity mode of the liquid-propellant engine with observation of the strength requirements on the rocket tanks. New principles enabling substantial improvement of the launcher potentialities were used and the requirements on unification of the launcher blocks were taken into consideration at designing the system of propellant consumption control and the pneumohydraulic propellant supply system. Program and checking facilities used in the technological chain of design and debugging of the launcher on-board software were developed. For substantial improvement of the life time in space of the oxigen-hydrogen acceleration engines of the advanced heavy launchers, new principles and algorithms were developed for the on-board systems of these engines (A.Ya. Andrienko and V.P. Ivanov).

Within the bounds of the Federal goal-oriented program "Destruction of Chemical Weapons in the Russian Federation":

- on the basis of the principles of modern complex inspection and analysis of the ecological situation in the zone of anthropogenic impact of the object of storage and destruction, the methodology of design of the system of industrial ecological monitoring of hazardous objects was developed, substantiated, and realized on three objects; methods enabling one to classify, identify, and forecast the ecological situations were developed using the on-line intelligent analysis;

- the methodology of design of the computer-aided simulators for training the personnel to control processes safely and efficiently by reproducing and analyzing the situations that may occur 
both in the standard mode and at failure and emergencies was developed and realized (V.G. Lebedev and Yu.S. Legovich).

The Institute has large contract with national and international companies, including those related with investment activity.

The young scientist school was founded at the Institute in 2007. Other forms of intensifying the financial support of the studies of young researchers are developed as well. Restored was the Council of Young Scientists and Experts which took active part in organizing and carrying out various competitions of the works of young scientists and youth scientific conferences on the Institute's subject matters. Four Dissertation Councils for eight specialties work at the Institute.

A number of international and national scientific and practical conferences and seminars on various fields of the control theory are held annually at the Institute. Hundreds of the leading Russian and international experts on control participate in them. In particular, the International Multiconference "Control Theory and Systems" organized by three institutes of the Russian Academy of Sciences (Institute of Control Sciences, Institute of Mechanical Problems, and Institute of System Analysis) was held in January 2009.

As over its entire glorious history, today the Institute remains the national leader in the science of control. The Editorial Board, editorial staff, and readers congratulate the Institute of Control Sciences and its workers on occasion of its jubilee!

Editorial Board of "Avtomatika i Telemekhanika" 